\title{
Supplier selection under uncertainty: A case study of home appliances maker
}

\author{
Tahereh Khodadadzadeh $^{\mathrm{a}^{*}}$, Reza Vadayeh Kheiri ${ }^{\mathrm{a}}$ and Seyed Jafar Sadjadi ${ }^{\mathrm{b}}$
}

${ }^{a}$ Department of Industrial Engineering (Digital Unit), Iran University of Science \& Technology, Tehran, Iran

${ }^{b}$ Department of Industrial Engineering, Iran University of Science \& Technology, Tehran, Iran, Member of Center of Excellent in Industrial Engineering

\section{H R O N I C L E}

Article history:

Received January 12, 2013

Received in revised format

10 April 2013

Accepted May 32013

Available online

May 32013

Keywords:

Supplier selection

Supply Chain Management

Goal programming

Fuzzy programming

\section{A B S T R A C T}

Many supply chain problems are involved with different parameters, which are under uncertainties. One of the primary concerns on supplier selection is to handle the uncertainty under different circumstances. The primary objective of this paper is to design a model to select suppliers and to determine the amount of purchase from any supplier in the supply chain system. For this purpose, we select the most important criteria using fuzzy questionnaires where the questionnaire uses experts' opinions in terms of linguistic values. Then, a hierarchy multiple criteria decision-making (MCDM) model based on fuzzy-sets theory is proposed to rank different suppliers and using a goal programming approach, we determine the amount of order product from each supplier. The implementation of the proposed model is demonstrated using a real-world case study.

\section{Introduction}

Supplier selection is one of the primary concerns on production planning and control (Khodadadzadeh \& Sadjadi, 2013). A good supplier could reduce product interruption, increase the quality of the final product and provide better customer satisfaction (Mohammadshahi, 2013). According to Phil Crosby, quality specialist, a major portion of most firms' quality problems is due to weak selection of suppliers. During the old days, many production managers were looking for cheap contracts but during the past two decades, it is recommended to first make an assessment on different suppliers and choose only the ones with high quality characteristics. Many supplier selection problems are investigated under uncertainty. Chen et al. (2006), for instance, presented a fuzzy decision-making technique to deal with the supplier selection problem in supply chain system. They used linguistic values to evaluate the ratings and weights for different factors involved with supplier selection. They expressed linguistic ratings in terms of trapezoidal or triangular fuzzy numbers and developed a hierarchy multiple criteria decision-making model based on fuzzy-sets theory to deal with the supplier selection problems in the supply chain system.

* Corresponding author. Tel: +9877240129

E-mail addresses: takhodadadzadeh@mail.com (T. Khodadadzadeh)

(C) 2013 Growing Science Ltd. All rights reserved. doi: $10.5267 /$ j.uscm.2013.05.002 
Dey et al. (2012) presented a MOORA based fuzzy multi-criteria decision making approach for supply chain strategy. Parsaei et al. (2012) presented an order acceptance using FAHP and TOPSIS methods for a case study of Iranian vehicle belt production industry selection. Kumar et al. (2004) implemented a fuzzy goal programming approach for solving the vendor selection problem with multiple objectives while they faced with a problem where some of the parameters were fuzzy in nature. They formulated a vendor selection problem as a fuzzy mixed integer goal programming vendor selection problem, which included three primary goals: minimizing the net cost, minimizing the net rejections, and minimizing the net late deliveries subject to some constraints on buyer's demand, vendors' capacity, vendors' quota flexibility, purchase value of items, budget allocation to individual vendor, etc.

Amid et al. (2006) presented a fuzzy multi-objective linear model to overcome the vagueness of the information. They used an asymmetric fuzzy-decision making technique in a fuzzy supplier selection problem to enable the decision-maker to assign various weights to various criteria. According to $\mathrm{Pi}$ and Low (2006), the purchasing function directly influences the competitive ability of a firm. Purchasing managers must periodically make an assessment on supplier performance to keep those suppliers who meet their requirements. Pi and Low (2006) provided a method for quantifying the supplier's attributes to quality-loss using a Taguchi loss function, and these quality losses were transferred into a variable for decision-making by an analytical hierarchy process.

One of the areas that most companies are concentrated is to manage the sourcing and procurement. There are many criteria including cost, quality and technology when the focus is on the management of the sourcing and procurement. Since most producers spend a large percentage of revenues on services, purchase is a major area for potential cost savings. The purchasing and supply chain management influence on quality, significantly. A supplier can provide the product or service that fails to meet or exceeds customer's expectations, which may cause serious damages on a company.

According to Monczka et al. (2008), purchasing cycle consists of the following steps:

1) identifies the need to purchase,

2) Evaluation of potential sources,

3) Select Supplier,

4) received and clearance requirements,

5) Evaluation of the continuous performance and supplier management.

New products need more time to evaluate potential sources and for selected items purchased from the suppliers, purchasing cycle, including identifying the need for purchasing, receiving material requirements, performance measurement and management is supplier. According to Gunasekaran et al. (2004) developed a framework to promote a better insight on the importance of supply chain management performance measurement and metrics. Korhonen and Siitari (2007) used lexicographic parametric programming to rank efficient units in the DEA model. They received the efficiency curve, which was traversing through the efficient frontier from unit to other unit and used the parameterization of the right-hand side vector of the cover problem. Lozano and Villa (2009) implemented AHP and lexicographic to specify a priori a set of preference levels.

Decision support system (DSS) has also been used for analyzing data and making appropriate decisions for supplier selection problem. Akçay et al. (2012), for instance, developed a general DSS model to investigate the results of implementation of DEA models. They examined the proposed model for a real world project for benchmarking the vendors of a leading Turkish automotive company.

In this paper, we present a method to use fuzzy analytical hierarchy process to rank different suppliers based on the relative importance. The study then uses goal programming technique to find the optimum level of production by considering different objectives. The organization of this paper is as 
follows. We first present the proposed method in section 2. Section 3 presents details of the implementation of the proposed model on a real-world case study and finally, concluding remarks are given in the last part to summarize the contribution of the paper.

\section{The proposed model}

\subsection{Analytic Hierarchy Process (AHP)}

Analytical hierarchy process (AHP) is one of the multi-criteria decision making problem where we ask decision maker to give his/her judgment about the relative priority of one's alternative versus another one. Saaty (1994) originally developed the method and it is a popular and widely used method for multi criteria decision making, which allows the implementation of qualitative as well as quantitative criteria in evaluation of alternatives (Calabrese et al., 2013).

Decision makers have to decompose the goal of the decision process into its constituent parts, progressing, from the general to the specific perspective. In its simplest form, this structure must incorporate goals, criteria and alternative levels, ordered into a hierarchy. Each criterion further is split down into an appropriate level of detail. Once the hierarchy is structured, decision makers judge the importance of each criterion in pair-wise comparisons, structured in matrices. The judgment is performed from the perspective of the direct upper level criterion. AHP technique performs an assessment based on experts' feedback and converts a complex decision into simple hierarchical system. The evaluation method is based on considering the relative importance of each criterion compared with other one.

Zeydan et al. (2011) proposed new method for selecting supplier selection and evaluation quality. They used FAHP to fine criteria weights and then fuzzy TOPSIS (Technique for Order Preference by Similarity to Ideal Solution) to utilize in finding the ranking of suppliers. So, qualitative variables were transformed into a quantitative variable for using in DEA methodology as an output called quality management system audit.

\subsection{Fuzzy set theory}

Zadeh (1996) introduced the idea of fuzzy set theory and addressed the problems of tackling the vagueness in information and the fuzziness in human perception. This concept emphasizes on approximate values rather than fixed and exact ones and various applications were generated by using fuzzy logic in recent years. In a universe of discourse $X$, a fuzzy subset $\tilde{A}$ of $X$ is defined with a membership function $\mu_{\tilde{A}(x)}$ that maps each element $x$ in $X$ to a real number in the interval $[0,1]$. A triangular fuzzy number (TFN) is shown in Fig. 4.

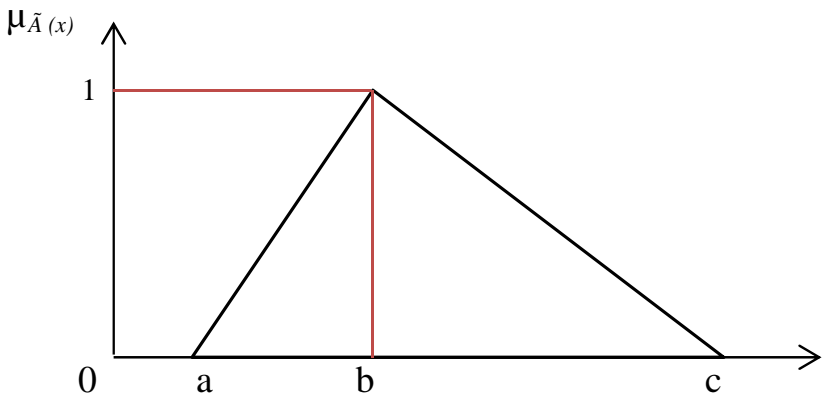

Fig. 4. Triangular Fuzzy Number

The function value of $\mu_{\tilde{A}(x)}$ signifies the grade of membership of $x$ in $\tilde{A}$. A triangular fuzzy number (TFN) $\tilde{A}$ can be defined as a triplet $(a, b, c)$ and the membership function is defined (Dubois \& Prade 1978; Keufmann \& Gupta 1991) as shown by Eq. (1). 
$\mu_{\tilde{A}(x)}=\left\{\begin{array}{cc}0 & x<a \\ (x-a) /(b-a) & a \leq x \leq b \\ (c-x) /(c-b) & b \leq x \leq c \\ 0 & x>c\end{array}\right.$

The concept of combining the fuzzy set theory and MCDM is stated as fuzzy MCDM. In fuzzy MCDM, performance rating of alternatives and weights of criteria are described in terms of linguistic terms. Linguistic variables are then transformed into either triangular, trapezoidal fuzzy numbers or range of fuzzy numbers.

\subsection{Gold Programming (GP)}

Goal programming is a multi-objective decision making (MODM) technique, which was first employed by Charnes and Cooper (1975). It can be thought as an extension of linear programming to solve problems containing multiple and usually conflicting objects. In gold programming model, we face with techniques of priority scheduling objective and techniques of utility function. In this method, we have two kinds of system limitations and ideal constraints. Goal programming model can be of the following form:

$\min \left[P_{1} h_{1}\left(d^{-}, d^{+}\right), \cdots, P_{l} h_{l}\left(d^{-}, d^{+}\right)\right]$

subject to

$$
\begin{aligned}
& g_{i}(x) \leq 0, i=1, \cdots, m \\
& f_{j}(x)+d_{j}^{-}-d_{j}^{+}=b_{j}, j=1, \cdots, k \\
& d_{j}^{-}, d_{j}^{+} \geq 0, j=1, \cdots, k \\
& d_{j}^{-} d_{j}^{+}=0, j=1, \cdots, k
\end{aligned}
$$

where $h_{l}\left(d^{-}, d^{+}\right)$states for deviation of $i^{\text {th }}$ constraints from the idea solution, $P_{l}$ represents a priority, $g_{i}(x)$ represents system limitation, $f_{i}(x)$ represents the ideal objective function, $d^{+}$and $d^{-}$represent positive and negative deviation from the ideal solutions, respectively.

\subsection{A hybrid method}

The proposed model of this paper uses the art of fuzzy programming to rank different criteria in terms of linguistic terms and applies the weights for a mathematical problem formulated in GP by considering some real-world circumstances.

\section{Case study}

In this section, we present the implementation of the proposed study using a real-world case study in home appliance makers named Haier Asa Co. located in Iran. The firm is the largest industrial companies in the Middle East in the production of refrigerators and freezers. Company provides its necessary materials from four suppliers located outside the country. The proposed study of this paper uses a questionnaire to collect experts' insights in terms of various criteria. The population used in the preparation of the questionnaire covers all employees of the Haier Asa Company from different departments including quality control unit, $R \& D$, production and inventory planning, logistics and production.

\subsection{List of criteria for supplier selection}

We have performed a comprehensive survey and detected 28 major criteria, which could influence supplier selection. Table 1 demonstrates details of all these criteria. 
Table 1

The summary of various criteria

\begin{tabular}{llll}
\hline No. & Criterion & No. & Criterion \\
\hline 1 & Close relationships & 15 & Strategic Assistance \\
2 & Company's reputation for honest & 16 & Quality \\
3 & Short delivery time & 17 & Delivery \\
4 & Technical capability & 18 & Deliver stable \\
5 & Continuous Improvement & 19 & Seller willing to trade \\
6 & Accountability company & 20 & Competitive position of the company \\
7 & Flexibility company & 21 & Environmental standards \\
8 & Asset management efficiency & 22 & Maintenance and Services \\
9 & Strategic fit & 23 & Location \\
10 & Estimation of future production & 24 & Financial conditions \\
11 & Supply rate of growth & 25 & Match Quality \\
12 & Personnel and organizational structure Supplier & 26 & Equipment and manufacturing capacity \\
13 & Price & 27 & Response time \\
14 & Historical record Performance & 28 & Long-term relationships \\
\hline
\end{tabular}

The proposed study of this paper uses fuzzy numbers for ranking different criteria. The proposed model of this paper uses trapezoid and triangular numbers specified in Table 2 as follow,

Table 2

Instruction of converting seven spectrums of fuzzy numbers

\begin{tabular}{|c|c|c|c|c|c|c|c|}
\hline linguistic variable & Very low & Low & More or less low & Average & More or less high & High & Very high \\
\hline Fuzzy number type & trapezoid & triangular & trapezoid & triangular & trapezoid & triangular & trapezoid \\
\hline Fuzzy number & $(0,0,0.1,0.2)$ & $(0.1,0.2,0.3)$ & $(0.2,0.3,0.4,0.5)$ & $(0.4,0.5,0.6)$ & $(0.5,0.6,0.7,0.8)$ & $(0.7,0.8,0.9)$ & $(0.7,0.9,1,1)$ \\
\hline Triangular number & $(0.0 .05,0.2)$ & $(0.1,0.2,0.3)$ & $(0.2,0.35,0.5)$ & $(0.4,0.5,0.6)$ & $(0.5,0.65,0.8)$ & $(0.7,0.8,0.9)$ & $(0.8,0.95,1)$ \\
\hline Certain number & 0.05 & 0.23 & 0.37 & 0.5 & 0.63 & 0.77 & 0.95 \\
\hline
\end{tabular}

We have categorized the products into four categories of strategic, lever, bottleneck and routine products and Table 3 demonstrates different criteria associated with each criterion.

Table 3

Selection criteria for each product group

\begin{tabular}{ll}
\hline Category of Products & Criteria \\
\hline & Quality \\
Strategic Products & Long-term relationships \\
& Delivery \\
& Price \\
& Supply rate of growth \\
& Price \\
Lever Products & Quality \\
& Delivery \\
& Long-term relationships \\
Bottleneck Products & Delivery \\
& Quality \\
& Long-term relationships \\
& Company's reputation for honest \\
Routine Products & Quality \\
& Delivery \\
& Price \\
\hline
\end{tabular}

The proposed model of this paper concentrates on compressor used in refrigerator as well as freezers and this part is considered as strategic product. Therefore, we only consider strategic product, which 
include five criteria represented in Table 3 and these criteria are ranked using fuzzy AHP and the results are summarized in Table 4 as follows,

\section{Table 4}

The summary of ranking criteria

\begin{tabular}{|c|c|c|c|}
\hline No. & Criterion & Supplier & Weight \\
\hline \multirow{4}{*}{1} & \multirow{4}{*}{ Quality(0.36) } & $\mathrm{S} 1$ & 0.035 \\
\hline & & $\mathrm{S} 2$ & 0.06 \\
\hline & & S3 & 0.02 \\
\hline & & S4 & 0.05 \\
\hline \multirow{4}{*}{2} & \multirow{4}{*}{ Long-term relationship relationships (0.177) } & S1 & 0.154 \\
\hline & & $\mathrm{S} 2$ & 0.09 \\
\hline & & S3 & 0.347 \\
\hline & & $\mathrm{S} 4$ & 0.409 \\
\hline \multirow{4}{*}{3} & \multirow{4}{*}{ Price $(0.28)$} & S1 & 1.15 \\
\hline & & $\mathrm{S} 2$ & 1.02 \\
\hline & & S3 & 1.08 \\
\hline & & S4 & 0.95 \\
\hline \multirow{4}{*}{4} & \multirow{4}{*}{ Supply rate of growth(0.113) } & $\mathrm{S} 1$ & 0.374 \\
\hline & & $\mathrm{S} 2$ & 0.87 \\
\hline & & S3 & 0.242 \\
\hline & & S4 & 0.297 \\
\hline & \multirow{4}{*}{ Delivery(0.07) } & S1 & 2.2 \\
\hline & & $\mathrm{S} 2$ & 4 \\
\hline & & S3 & 3.3 \\
\hline & & $\mathrm{S} 4$ & 4.7 \\
\hline
\end{tabular}

\subsection{Production planning based on goal programming}

Now that we know the relative importance of each four suppliers in terms of various criteria, we consider some practical limitations on each supplier and propose a goal programming technique to rank them, accordingly. Let $x_{i}$ be the amount of products ordered from $\mathrm{i}^{\text {th }}$ supplier, $\mathrm{i}=1,2,3,4$. Therefore, the first constraint is as follows,

$\sum_{i=1}^{4} x_{i}=100,000$

There are also some limitations on each supplier for ordering products, which are summarized as follows,

$x_{2} \leq 50,000$

Based on the feedback received from experts, there is a limit of $65 \%$ for each supplier. Therefore we have,

$x_{i} \leq 65,000 \quad i=1,2,3,4$

The goal constraint associated with price criterion is as follows,

$1.15 x_{1}+1.02 x_{2}+1.08 x_{3}+0.95 x_{4}+d_{1}^{-}-d_{1}^{+}=100,000$

The other goal constraint is related to quality and it is specified as follows,

$0.035 x_{1}+0.06 x_{2}+0.02 x_{3}+0.05 x_{4}+d_{2}^{-}-d_{2}^{+}=0.03(100,000)$

We have determined that the maximum delivery time is three days and it is specified as follows, 
$2.2 x_{1}+4 x_{2}+3.3 x_{3}+4.7 x_{4}+d_{3}^{-}-d_{3}^{+}=3(100,000)$

In terms of long-term relationship, the desirable coefficient is 0.35 , which yields,

$0.154 x_{1}+0.09 x_{2}+0.347 x_{3}+0.409 x_{4}+d_{4}^{-}-d_{4}^{+}=0.35(100,000)$

Finally, for supply rate of growth we have,

$0.374 x_{1}+0.087 x_{2}+0.242 x_{3}+0.298 x_{4}+d_{5}^{-}-d_{5}^{+}=2.5(100,000)$

Now, we can solve the GP problem using the model stated in Eq. (2). The model can be solved by any linear programming package, very easily. The results indicate that the firm could reach its objectives of quality, delivery and supply rate of growth, completely. However, the firm could not reach its long-term relationship as well as price and there were deviation from these two goals of 6188 and 9770, respectively.

\section{Conclusion}

Supply chain management plays an important role on producing better quality products. It can help increase productivity of the firms by reducing male function parts, delays, product interruption, etc. In this paper, we have presented an empirical investigation for supplier selection. The proposed study has chosen fuzzy numbers to compare different criteria based on fuzzy AHP. The proposed study of this paper has used the resulted weights for a goal programming model to find the desirable order product. As a case study, we have applied the proposed model of this paper on a real-world case study where the firm was planning to find optimum number of supplier of supplier for a strategic product as well as the order size from each supplier. The results of our application have revealed that the proposed model could help resolve uncertainty on supply chain management and it could help us find better suppliers for production planning.

\section{References}

Akçay, A.E., Ertek, G., \& Büyüközkan. (2012). analyzing the solutions of DEA through information visualization and data mining techniques: Smart DEA framework. Expert Systems with Applications, 39(9), 7763-7775.

Amid, A., Ghodsypour, S. H., \& O’brien, C. (2006). Fuzzy multiobjective linear model for supplier selection in a supply chain. International Journal of Production Economics, 104(2), 394-407.

Calabrese, A., Costa, R., \& Menichini, T. (2013). Using fuzzy AHP to manage intellectual capital assets: An application to the ICT service industry. Expert Systems with Applications, 40, 37473755.

Charnes, A., \& Cooper, W. W. (1975). Goal programming and constrained regression-A comment. Omega, 3(4), 403-409.

Chen, C. T., Lin, C. T., \& Huang, S. F. (2006). A fuzzy approach for supplier evaluation and selection in supply chain management. International Journal of Production Economics, 102(2), 289-301.

Dey, B., Bairagi, B., Sarkar, B., \& Sanyal, S. (2012). A MOORA based fuzzy multi-criteria decision making approach for supply chain strategy. International Journal of Industrial Engineering Computations. 3, 649-662.

Dubois, D., \& Prade, H. (1997). Using fuzzy sets in flexible querying: Why and how?. In Flexible Query Answering Systems (pp. 45-60). Springer US.

Gunasekaran, A., Patel, C., \& McGaughey, R. E. (2004). A framework for supply chain performance measurement. International journal of production economics, 87(3), 333-347.

Kabir, G. \& Akhtar Hasinb, M.A. (2012). Framework for benchmarking online retailing performance using fuzzy AHP and TOPSIS method. International Journal of Industrial Engineering Computation, 3, 561-576. 
Keufmann, A., \& Gupta, M. M. (1991). Introduction to fuzzy arithmetic: Theory and application. NY: Van Nostrand Reinhold.

Korhonen, P.J., \& Siitari, (2007). Using lexicographic parametric programming for identifying efficient units in DEA. Computers \& Operations Research, 34(7), 2177-2190.

Kumar, M., Vrat, P., \& Shankar, R. (2004). A fuzzy goal programming approach for vendor selection problem in a supply chain. Computers \& Industrial Engineering, 46(1), 69-85.

Khodadadzadeh, T., Sadjadi, S.J. (2013). A state-of-art review on supplier selection problem. Decision Science Letters, 2 (2), 59-70.

Lozano, S., \& Villa, G. (2009). Multiobjective target setting in data envelopment analysis using AHP. Computers \& Operations Research, 36(2), 549-564.

Mohammadshahi, Y. (2013). A state-of-art survey on TQM applications using MCDM techniques. Decision Science Letters, 2 (3), 125-134.

Monczka, R. M., Handfield, R. B., \& Giunipero, L. C. (2008). Purchasing and supply chain management. South-Western Pub.

Parsaei, S., Keramati, M.A., Zorriassatine, F., \& Feylizadeh, M.R. (2012). An order acceptance using FAHP and TOPSIS methods: A case study of Iranian vehicle belt production industry selection. International Journal of Industrial Engineering Computations, 3, 211-224.

Pi, W. N., \& Low, C. (2006). Supplier evaluation and selection via Taguchi loss functions and an AHP. The International Journal of Advanced Manufacturing Technology, 27(5-6), 625-630.

Saaty, T.L. (1994). Fundamentals of decision making and priority theory with the analytical hierarchy process. RWS Publications, Pittsburgh, PA.

Zadeh, L. A., Klir, G. J., \& Yuan, B. (1996). Fuzzy sets, fuzzy logic, and fuzzy systems: Selected papers (Vol. 6). World Scientific Publishing Company.

Zeydan, M., Çolpan, C., \& Çobanoglu., C. (2011). A combined methodology for supplier selection and performance evaluation. Expert Systems with Applications, 38(3), 2741-2751. 